\title{
A QUESTÃO DA DISTINÇÃO FATO/VALOR E O REALISMO MORAL DE ALASDAIR MACINTYRE ${ }^{1}$
}

\author{
The question of Fact/Value distinction and the Alasdair Maclntyre's Moral Realism
}

João Caetano Linhares

UFMA/UFSM

\begin{abstract}
Resumo: Entre os vários problemas filosóficos que tem ocupado os filósofos envolvidos com a pesquisa ética está aquele da objetividade do valor. Alguns teóricos defendem que não há objetividade nos juízos valorativos. Outros, os realistas, defendem que os juízos valorativos são tão objetivos quanto os juízos factuais. Aqui abordaremos a postura realista, em especial o realismo naturalista de Alasdair Maclntyre, e como esta postura lida com a questão da distinção entre fato e valor.
\end{abstract}

Palavras-Chaves: Fato, valor, realismo, Maclntyre, Moral.

Abstract: Among the more significant problems of current moral philosophy is the distinction between Fact and Value, if value judgments can receive objective force. Some have proposed that there is no objectivity in value judgment. Others, the realist ones, claim that value judgments are as objective as the factual judgment. Hence, we will approach the realist standpoint, more strictly the Maclntyre's natural realism and how that standpoint deals with the fact/value distinction.

Key words: Fact, Value, Realism, Maclntyre, Moral.

\section{Introdução}

A distinção filosófica entre facto e valor já aparece, assim podemos dizer, desde a antiguidade, quando se distingue entre physis e ethos. Physis seria o reino no qual as coisas são e não podem não ser, ou seja, é o reino da necessidade. Enquanto, o ethos seria o reino no qual as coisas são, mas podem ser diferentes, o reino da

\footnotetext{
1 Trabalho financiando pela Fundação de Amparo à Pesquisa e ao Desenvolvimento Científico e Tecnológico do Estado do Maranhão (FAPEMA).
} 
liberdade. Em termos modernos a physis (natur) seria o reino dos factos e o ethos (geist) seria o reino dos valores. Tal distinção servia para não tratarmos como iguais coisas que são, em si mesmas, diferentes. Não podemos, assim diz Aristóteles ${ }^{2}$, exigir o mesmo grau de clareza e precisão em todos os assuntos de modo igual.

Aqui podemos perceber que há uma mudança no modo como a modernidade compreende o ethos, este entendido como mundo dos valores. A modernidade, desde que considerada como uma tradição de pesquisa coerente, que possui um background que unifica os intentos filosóficos daqueles pensadores considerados modernos, é marcada pelo projeto de encontrar critérios e padrões neutros e universais de racionalidade. É no horizonte do pensamento moderno e de suas pretensões de cientificidade que surge o problema da relação entre fato e valor, assim como as questões metodológicas que acompanham esta distinção.

O projeto epistemológico da modernidade terá como resultado a destituição do ethos como lugar de conhecimento objetivo. O mundo dos valores será relegado ao âmbito do meramente subjetivo. Daí resulta a questão: os valores são objetivos ou não? Esta é a pergunta que deve ser determinada em primeiro lugar por aqueles que se aventuram na pesquisa ética.

Quem determina de modo substancial a distinção ${ }^{3}$ entre fato e valor nesse contexto é o filósofo inglês $D$. Hume. E isto a tal ponto que a distinção pode ser chamada, e na verdade tem sido reconhecida deste modo, de "o princípio de Hume" ou "a guilhotina de Hume" e consiste na distinção entre descritibilidade factual e normatividade valorativa, defendendo uma posição que considera impossível a dedução normativa a partir de fatos. No seu Tratado da Natureza Humana, Livro III, parte I, seção I, Hume afirma o seguinte:

\footnotetext{
${ }^{2}$ Cf. Metafísica I; Ética à Nicômaco I; Tópica II. Na verdade esta ideia já se encontra no próprio Platão, cf. Menon e Górgias.

${ }^{3}$ Distinção que será compreendida como dicotômica.
} 
Não posso deixar de acrescentar a esses raciocínios uma observação que talvez se mostre de alguma importância. Em todo sistema de moral que até hoje encontrei, sempre notei que o autor segue durante algum tempo o modo comum de raciocinar, estabelecendo a existência de Deus, ou fazendo observações a respeito dos assuntos humanos, quando, de repente, surpreendo-me ao ver que, em vez das cópulas proposicionais usuais, como é e não é, não encontro uma só proposição que não esteja conectada a outra por um deve ou não deve. Essa mudança é imperceptível, porém da maior importância. Pois, como esse deve ou não deve expressa uma nova relação ou afirmação, esta precisaria ser notada e explicada; ao mesmo tempo seria preciso que se desse uma razão para algo que parece inteiramente inconcebível, ou seja, como essa nova relação pode ser deduzida de outras inteiramente diferentes. Mas já que os autores não costumam usar essa precaução, tomarei a liberdade de recomendá-la aos leitores; estou persuadido de que essa pequena atenção seria suficiente para subverter todos os sistemas correntes de moralidade, e nos faria ver que a distinção entre vício e virtude não está fundada meramente nas relações dos objetos, nem é percebida pela razão (HUME, 2000, p. 509).

Hume começa esta seção defendendo a ideia de que a moral está excluída da razão. Que a razão lida com o fato e o verdadeiro, e que a falsidade e a veracidade dizem respeito à existência e aos fatos reais. A moral é, assim, reduzida ao reino das volições, paixões e ações. Ninguém pode dizer, de modo consequentemente lógico, que uma ação, ou uma paixão ou uma volição é falsa ou verdadeira. Deste modo, Hume expõe a mais forte distinção entre fato e valor, entre ser e dever-ser.

Da distinção fato/valor, podemos dizer, que derivam as duas principais correntes das teorias que possuem a tarefa de fundamentar as pesquisas éticas: aquelas que apostam numa continuidade entre ciência/ser e ética/dever-ser (cognitivismo) e aquelas que defendem uma descontinuidade entre ser e dever-ser (não-cognitivismo).

Nos ocuparemos aqui de um dos tipos que defende uma continuidade entre ser e dever-ser. Tal tipo de teoria é reconhecida como realismo.

\section{Realismo: Suavizando Factos, Reforçando Valores}


Podemos começar nos questionando: "para o quê o realismo moral é uma resposta?". É comum em algumas posturas éticas se pensar que basta a coerência ou, pelo menos, a plausibilidade lógica para afirmar uma postura como correta. Todavia, é possível perceber rapidamente que não é bem assim. A postura realista surge, e se mantém, no enfrentamento de posturas subjetivistas (pelo menos o realismo que tratamos aqui), tais como o emotivismo ou o expressivismo, por exemplo. Assim, devemos ter claro desde o início que o que classifica uma teoria como realista é a tarefa de provar que os valores são objetivos. Ou seja, que os valores não são simples expressões de nossas emoções ou preferencias pessoais, nem dependem apenas do endosso e da aceitação de normas.

Putnam é um dos pensadores centrais para a compreensão do realismo, principalmente do seu aspecto descritivo. Ou seja, ele procura demostrar que o realismo possui uma carga descritiva eficaz. Chama nossa atenção para o modo como decidimos entre uma teoria ou outra. Recorrendo ao exemplo do desacordo entre as teorias da gravitação de Einstein e Whitehead, que foi rejeitada cinquenta anos antes que fossemos capazes de produzir um experimento decisivo entre os dois modelos teóricos, Putnam evidencia que os fatos não são tão decisivos quanto se pensa para a resolução de desacordos. A noção de racionalidade, como algo neutro, sofre mudanças na avaliação putnaniana.

Às vezes a decisão pode ser tomada baseada em um desiderato tal como simplicidade (na teoria de Einstein pareceu ser mais "simples" de ir da relatividade especial à uma explicação da gravitação do que a de Whitehead) algumas vezes baseadas no conservativismo (momentum foi definido por Einstein de modo que a lei da conservação do momentum poderia ser conservada em colisões elásticas); e "simplicidade" e "conservação" são, elas mesmas palavras para fenômenos complexos que variam de situação para situação (PUTNAM, 1992, p.138). 
O que Putnam defende é que palavras ${ }^{4}$ que são usadas para indicar racionalidade descritiva/objetiva, tais como: "coerência", "simples", "justificação" e outras do mesmo tipo, que são usadas para expor racionalidade tem o mesmo estatuto de objetividade de palavras tais como "coragem", "gentileza", "honestidade". Ou seja, tanto "coerente" quanto "honesto" reivindicam objetividade racional no seu uso.

Desta forma, Putnam nos mostra que o realismo moral possui a mesma capacidade descritiva do realismo epistemológico, que dizer que algo é justificável significa o mesmo que dizer que é aceitável racionalmente, e dizer que algo é bom significa o mesmo que dizer que é aceitável racionalmente. Ou seja, ambos os usos apelam para uma objetividade. Quando alguém diz "foi corajoso" não está dizendo "gostei desta ação", mas reconhecendo que tal ação foi valiosa, objetivamente valiosa. E Putnam complementa:

\begin{abstract}
Nossa visão sobre a natureza da coerência e simplicidade são historicamente condicionadas, do mesmo modo que nossa visão da natureza da justiça ou da bondade são. Não há nenhuma concepção neutra de racionalidade à qual possamos apelar quando a natureza da própria racionalidade é que está em questão ${ }^{5}$ (PUTNAM, 1992, p.139).
\end{abstract}

Devemos notar que na consideração do realismo como uma descrição adequada dos nossos usos de termos morais há uma concepção de historicidade que permeia tais usos. Na reconsideração dos valores como objetivos há uma reconsideração da natureza da racionalidade humana ela própria. A razão não pode ser considerada como os pensadores tipicamente modernos a consideraram, como elemento frio e calculador. Por isso, quando Putnam diz que não podemos apelar para critérios racionais neutros para decidirmos nossos desacordos ele está apontado para a questão de que a própria natureza da racionalidade é um problema.

\footnotetext{
${ }^{4}$ Cf. Davidson, D. On a very ideia of a conceptual scheme (1974) para esta noção de um vocabulário científico que determina, até certo ponto, nossas experiências de mundo e dá forma a tais experiências. ${ }^{5}$ Grifo nosso.
} 
A questão para o realista é que as ciências sociais e a antropologia têm nos mostrado que a razão não é absoluta, ou seja, que os padrões de racionalidade mudam de uma cultura para outra e esta constatação empírica enseja a postura relativista. Putnam procura rejeitar a postura relativista apelando simplesmente para a lógica ao afirmar que o relativismo é auto-refutante, pois defende que não há verdade fora dos padrões de racionalidade das diversas culturas, e ainda assim pretende que isto seja uma verdade que transcende a estes padrões. No entanto, o relativismo é muito plausível, a despeito da lógica, e possui fortes evidências empíricas a seu favor ${ }^{6}$

O que podemos tirar de lição das reflexões de Putnam é que o conceito de racional vai muito além do conceito de científico. Com isto ele reivindica racionalidade para os valores, ou seja, objetividade, que corresponde aos nossos usos cotidianos dos termos valorativos. Tanto o emotivismo, expressivismo, prescritivismo quanto o positivismo descrevem inadequadamente esse uso.

Para que fique mais claro, no nível de fundamentação da pesquisa ética, os que defendem posturas antirrealistas afirmam ou defendem que a decisão de tentar ser "bom" ou tentar fazer "o bem" é apenas uma escolha de modo de vida. Entretanto, no nível ético, da ação propriamente dita, sempre defendemos o "certo" e reprovamos o "errado", e pretendemos fazê-lo de modo racional. Não dizemos simplesmente que é uma escolha diferente da nossa, mas tentamos, na maioria das vezes, argumentar em defesa de nossas posições. Essa incoerência entre o que podemos justificar e defender no nível metaético e aquilo que fazemos no mundo faz do realismo uma teoria mais adequada do que as de seus opositores. Como Putnam afirma: "Eu sustento, em resumo, que sem valores não teríamos um mundo" (1992, p.141).

\section{Maclntyre e a Questão da Objetividade do Valor}

6 Voltaremos a questão do relativismo mais a baixo. 
Como já observamos acima, a análise de Putnam, apesar de encaminhar a questão da distinção facto/valor e evidenciar que tal distinção está fundada numa concepção inadequada de racionalidade, deixa em aberto muitas outras questões mais específicas sobre o realismo moral. E, além disso, resta a questão do relativismo que não encontramos um argumento, em Putnam, mais sólido do que a objeção que se baseia na contradição lógica.

Um outro realista que pode nos fornecer mais meios de acatarmos essa concepção de objetividade normativa (junto a noção de racionalidade putnaniana) e, ainda, evitarmos o relativismo é o escocês Alasdair Maclntyre. ${ }^{7}$ Nossa exposição do realismo de Maclntyre passa pelo enfrentamento de três objeções contra as teorias realistas: a) a Determinabilidade Racional dos juízos de valor; b) A Estranheza Ontológica (ontological queerness); c) Internalismo.

A questão da determinabilidade racional é um dos principais desafios para aqueles que assumem a tarefa de compreender e explicar o papel que os valores representam em nossa vida. Com MacIntyre não é diferente. De fato, os pensadores que defendem a distinção entre fato e valor estão baseados na incapacidade sistemática de dar um encaminhamento racional para os desacordos morais; afirmam que em questões factuais as disputas e desacordos podem ser resolvidos por apelo a demonstração racional e experiências. Já no que diz respeito a questões de valor, aqueles que estão em desacordo podem ser pessoas racionais e, mesmo assim, não conseguem resolver seus desacordos.

Este problema é na verdade uma das primeiras preocupações de Maclntyre já no início de seu projeto "After Virtue" desacordos morais e o porquê de nossa sistemática incapacidade de resolvê-los. O seu

\footnotetext{
${ }^{7}$ Temos consciência que em seus últimos trabalhos, Maclntyre tem defendido uma noção mais "forte" de realidade. Uma espécie de realismo metafísico mais ligado á concepção cristã de Tomás de Aquino. No entanto, aqui consideraremos a postura macintyriana como uma espécie de realismo relacional e naturalista.

${ }^{8}$ Para maiores detalhes sobre a concepção do projeto "after virtue" conferir o artigo da professora Damasceno: O Projeto Filosófico Central de Alasdair Maclntyre, 2011.
} 
diagnóstico distingue três características do desacordo moral contemporâneo ${ }^{9}$ : a primeira consiste na incomensurabilidade entre os diversos pontos de vista morais rivais, ou seja, todos se apresentam de modo logicamente ordenados, ou podem ser expandidos até se tornarem. No entanto, as premissas são tais que não possuímos um modo neutro de avaliação entre tais pontos de vista. Esta constatação é a mesma que leva os anti-realistas a afirmarem que devido a isto não há objetividade alguma nos juízos valorativos. Outro aspecto desta primeira característica é que a lógica é insuficiente para determinar a aceitabilidade racional maior de um ou outro ponto de vista.

A segunda característica é que, não obstante, a patente incapacidade de resolução dos desacordos morais, há uma pretensão de neutralidade racional nos diversos pontos de vista envolvidos no debate. Tal pretensão se mostra na postura de impessoalidade com a qual os argumentos são expostos. Esta característica pode sustentar uma concepção relativista dos valores morais, uma vez que os argumentos só possuiriam esse caráter de impessoalidade na cultura que compartilha os mesmos padrões de justificação, claro que este seria um resultado indesejado. E junto com esta concepção de impessoalidade viria uma ética da tolerância que nos levaria a aceitar os maiores absurdos.

Por fim, a terceira característica identificada por Maclntyre está estritamente relacionada com as duas anteriores: "É fácil notar que as diferentes premissas conceptualmente incomensuráveis dos argumentos rivais empregadas nestes debates têm uma ampla variedade de origens históricas" (MACINTYRE, 2007, p.10).

Estas características são amplamente desenvolvidas por Maclntyre em seu trabalho "Whose Justice? Which Rationality?" (1988), no qual busca evidenciar justamente a Determinabilidade racional dos juízos morais. Maclntyre, a partir de seu diagnóstico, procura determinar o estatuto da moralidade, compreendida como um sistema de normatividade objetiva.

${ }^{9} \mathrm{Cf}$. Maclntyre, 2007, p. 8ss 
Seguindo as conquistas das ciências sociais do século XX, ele não nega que há um certo grau de relativismo nas origens das tradições culturais, que por sua vez incorporam tradições morais, que por sua vez implicam tradições de pesquisa moral (ética). Então, uma vez que temos uma diversidade de origens históricas que determinam os nossos modos e padrões de racionalidade, não temos uma racionalidade, mas racionalidades.

Neste caso, não há um padrão neutro e universal para "medir" que postura é mais ou menos racional que as outras. ${ }^{10}$ Todos os padrões são internos a estas tradições. O relativismo venceu, então? A resposta é: não. Cada uma destas tradições carrega consigo a pretensão de universalidade. Ou seja, o que não existe são padrões neutros, universais e a priori tais como os partidários do projeto moderno pretendiam estabelecer.

O que derrota o relativismo, na perspectiva de Maclntyre, é o fato de que os partidários dos diversos pontos de vista envolvidos nos debates pretendem superar seus rivais. O desafio dele será mostrar como isto é possível. Esta demonstração é que mostra qual o grau de Determinabilidade racional dos juízos valorativos.

Os autores antirrealistas defendem que o que diferencia fatos e valores é que os factos se impõem pela experiência, há uma causalidade no mundo que se impõe contra nossas preferências e aspirações. E que isso não se verifica no âmbito dos valores. Maclntyre irá defender que os valores também são descobertos com a experiência e, acompanhando o que dissemos sobre Putnam, os valores possuem o mesmo estatuto epistêmico dos fatos.

Desta forma, a crítica da indeterminabilidade racional $^{11}$ é superada por Maclntyre ao evidenciar que não existem critérios de racionalidade para além dos esquemas conceituais das diversas tradições. No entanto, para evitar o relativismo ele

\footnotetext{
${ }^{10}$ Sobre a possibilidade do debate entre tradições e um tratamento mais adequado da questão do relativismo, C.f. o meu texto: "O teste histórico-dialético das tradições de pesquisa moral na filosofia de Alasdair Maclntyre" (2014).

${ }^{11}$ Sobre o estatuto da racionalidade em Alasdair MacIntyre, cf.: MacIntyre, 2008a, p. 349ss; Maclntyre, 2006, p. 56ss; Maclntyre, 2008b, p. 53ss.
} 
admite que existem esquemas conceituais superiores a outros. O problema é como esta superioridade pode ser demonstrada de modo que a outra tradição reconheça sua inadequação.

Para encaminhar este problema para uma possível solução Maclntyre explicita o modo de funcionamento das tradições de pesquisa. Uma tradição de pesquisa possui uma estrutura teleológica, parte de princípios primeiros e se dirige para um fim último. Os primeiros princípios são estabelecidos até certo ponto de modo contingente, mas devem se justificar no decorrer da pesquisa. Uma tradição é considerada bemsucedida se o conjunto de suas explicações sobre seus objetos de estudo são adequadas. Quando uma tradição começa por qualquer motivo a apresentar problemas no que diz respeito às suas capacidades explicativas e investigativas ela entra numa "crise epistemológica". Uma crise epistemológica ocorre quando os critérios e padrões de investigação de uma tradição parecem não mais corresponder de modo adequado aos seus objetos.

Uma crise pode ser resolvida a partir dos próprios recursos da tradição que está em crise. Pode ser resolvida a partir de recursos de uma tradição rival, por meio de uma fusão de horizontes. Ou, também pode acontecer que a tradição se mostre sistematicamente incapaz de resolver sua crise e fracasse como tradição racional. Claro que pode ocorrer que os partidários de uma tradição que perdeu sua capacidade racional não percebam que isto ocorreu e permaneçam por um longo tempo ainda tentando trabalhar por meio de seus padrões.

Devemos estar atentos para o aspecto narrativo da justificação racional. Não há critério racional a priori esperando ser descoberto. Nem devemos pensar que tais critérios são fruto da imaginação. Os critérios, e sua adequação, são descobertos no enfrentamento dos problemas e entre as tradições de pesquisa. Por isso pode acontecer de duas tradições de pesquisa mais amplas permanecerem por um longo período em disputa sem que as evidências capazes de pôr fim às disputas sejam estabelecidas. 
Deste modo, a determinabilidade racional do valor possui para Maclntyre um aspecto social, pois o "bem" é descoberto com os outros que também estão engajados na busca deste bem, o que dá um caráter de objetividade aos valores. Mas a explicação do "bem" deve transcender o âmbito do social, há um caráter ontológico na explicação do bem. Aquilo que é bom não é só bom para determinadas pessoas, nem é bom absolutamente. $\mathrm{O}$ pensamento de Maclntyre transita entre o relativismo e o absolutismo de valor. MacIntyre crê que existe um bem que pertence à natureza humana, mas este bem não pode ser descoberto a priori. É motivo de busca.

O segundo aspecto que falamos acima: da estranheza ontológica, que consiste no argumento de que de nenhuma afirmação factual pode derivar uma afirmação valorativa, de nenhum "é" deriva um "deve". Maclntyre enfrenta este desafio por meio do que ele chama de conceito funcional. De fato, esta ideia já está em Aristóteles, no início de sua Ética a Nicômaco o estagirita afirma que todas as coisas possuem um ergon, uma função ou bem. É a partir deste conceito funcional que Maclntyre prova que de fatos podem ser estabelecidos valores.

\begin{abstract}
De premissas factuais como "Ele tem a melhor produção por hectare nesta plantação do que qualquer outro agricultor deste distrito", "Ele tem o mais eficiente programa de renovação da terra que se conhece" e "O gado leiteiro dele ganha todos os prêmios das exposições de agropecuária", a conclusão normativa válida é "Ele é um bom agropecuarista". [...] $\mathrm{Na}$ tradição aristotélica afirmar que $x$ é bom (onde $x$ pode ser entre outras coisas uma pessoa ou um animal ou um estado de humor) é também dizer que é o tipo de $x$ que alguém escolheria se estivesse procurando um $x$ para o propósito para o qual $x$ é caracteristicamente procurado. (MACINTYRE, 2007, p. 58-59).
\end{abstract}

Ou seja, para Maclntyre o bem é uma propriedade natural, que pertence ao sentido das coisas. Algo é bom se cumpre a função para a qual foi designado. Claro que aqui permanece a ideia de um bem relacional, só há valor no mundo porque há seres que valoram. Mas os valores são objetivos e não dependem da mera vontade e desejos dos indivíduos. 
Devemos agora distinguir entre dois níveis de valoração. Esse valor que possui evidências empíricas de que é real, que possui uma espécie de feedback do mundo real. E outro nível de valoração que não possui justificação empírica e mesmo assim algumas classes de pessoas os têm como verdadeiros, por exemplo, considerar que a água benta possui propriedades sagradas. Esse segundo nível de valoração não possui, deve estar claro, o mesmo grau de objetividade do "bom fazendeiro" de MacIntyre.

Da mesma forma que no nível factual são feitas conexões que não podem ser comprovadas empiricamente, ou não se tem forte evidências de que são verdadeiras, no nível valorativo também podem existir crenças que não possuem força justificativa. Esse tipo de valoração não deriva de fatos, nem está ligado a eles.

O outro tipo de objeção a teoria realista seria o internalismo de valor. 0 internalismo de valor é a inversão do realismo. Os partidários do internalismo, tanto kantianos quanto humeanos, defendem que para um juízo normativo possuir força para um indivíduo o cumprir, este indivíduo deve ter alguma razão para obedecê-lo.

\footnotetext{
Tem sido defendido tanto por humeanos quanto por kantianos que para que um juízo normativo seja aplicado a um indivíduo, ele deve ter uma razão não necessariamente primordial - para obedecê-la. Esta tese faz uso da noção de ter uma razão, e assim ela pode tomar várias formas dependendo da concepção de racionalidade pressuposta. Um kantiano pode exigir que o juízo normativo seja uma máxima da vontade racional de um indivíduo. Um humeano pode exigir que o indivíduo tenha algum desejo ou fim relativo ao qual há razão instrumental para obedecer ao juízo. (RAILTON, 1986, p.7)
}

Esse nível de objeção subjetivista é tratado por Maclntyre como teorias que restringe a normatividade à mera expressão de preferências dos indivíduos. Dizer que "eu prefiro x" é diferente de dizer "x é bom". A noção de bom está para além da concordância de indivíduos particulares. Algo não se torna correto, nem incorreto, por causa da vontade dos indivíduos. Pelo contrário, como já apontamos, o bem é objeto de busca coletiva.

O estatuto do bem é definido, em primeira instância, pela natureza do ser humano. O bem humano é diferente dos bens das outras espécies, apesar de 
compartilharmos muitos aspectos naturais com outras espécies. Neste sentido, a explicação que Alasdair Maclntyre dá, em seu texto "Dependent Rational Animals" (1999), busca evidenciar justamente o aspecto da objetividade/externalidade do bem. Há, assim afirma Maclntyre, uma hierarquia de bens, organizados numa hierarquia de práticas sociais específicas nas quais os seres humanos são inseridos desde crianças. Aliás, esta é uma característica distintiva do projeto macintyriano: o ser humano não nasce eticamente educado, ele passa por todo um processo de educação intelectual e moral até poder ser considerado, pelos outros que o cercam e com os quais compartilha um mundo, um indivíduo raciocinador independente.

É no interior das diversas práticas sociais que o indivíduo aprende a diferenciar entre os diversos bens disponíveis e quais ele deve buscar, e ainda a diferenciar o seu bem, isso se ele for um bom aprendiz, enquanto filho, irmão, pedreiro, marido, etc., e o seu bem enquanto ser humano. Ele também deve aprender a distinguir o seu bem enquanto aprendiz do bem aperfeiçoado do mestre. Aqui surge a importância da autoridade, que agora não é considerada arbitrária, mas se justifica no reconhecimento que o outro está mais bem preparado do que eu para tratar de algum assunto.

Obviamente, esse processo de educação pode fracassar, e em nossas sociedades "avançadas" tem fracassado em inúmeros casos. Pode ser que a criança não seja educada da maneira adequada e não consiga aprender quando mudar de opinião frente a evidências e, assim, não consiga avançar na busca do bem.

Desta forma, fica claro que a noção de bem não é absoluta nem pode ser intuída a priori. A noção de bem abordada pelo tipo de realismo naturalista de Alasdair Maclntyre é relacional. Algo é bom para um determinado indivíduo em determinadas circunstâncias. Nada é bom em si mesmo ou por si mesmo. Algo se torna bom se cumpre a função para a qual alguém desejaria aquela coisa. E esta função é independente do conjunto motivacional de um sujeito. 
O juízo normativo possui validade independente da vontade racional do sujeito, ou do conjunto de interesses particulares, ou até coletivos que o indivíduo possa ter. Os bens possuem sua estabilidade objetiva nas diversas práticas sociais ${ }^{12} \mathrm{e}$ na ideia de um bem comum da natureza humana. Embora este último aspecto sirva mais como sentido da vida humana do que algo que se possa alcançar de modo definitivo. O bem humano consiste na busca do bem humano. Ou seja, a excelência do ser humano é exercer sua capacidade racional de buscar o seu bem enquanto ser humano; e tal busca é coletiva, não é uma busca solitária.

Mesmo que o indivíduo, apesar de reconhecer que um juízo valorativo é verdadeiro, não cumpra tal juízo por não estar interessado, isto não invalida a força normativa do juízo. E no âmbito das diversas práticas sociais existem os fins/bens que devem ser alcançados. Estes fins já estão objetivamente postos pela tradição da prática social em questão. E pela tradição sociocultural da qual o indivíduo é parte desde o seu nascimento. Cabe a tal indivíduo se engajar de modo adequado na busca do bem comum e seu próprio.

\section{Conclusão}

Procuramos evidenciar neste trabalho em que consiste a postura realista e como a noção de racionalidade é concebida por um dos destacados filósofos realistas, Putnam. No entanto, a análise de Putnam esbarra em algumas pressuposições. A avaliação que ele faz da auto-refutação do relativismo o impede de buscar uma solução mais adequada para o problema.

Neste sentido, Maclntyre expressa uma noção de racionalidade alinhada com a de Putnam, e acaba indo além em suas reflexões. Faz isso ao dar um tratamento mais adequado do relativismo, assumindo toda sua carga empírica e recusando a conclusão. A partir disso, vimos que é possível extrair da postura macintyreana respostas contra

\footnotetext{
12 Para uma discussão sobre a relação do indivíduo com as práticas sociais, virtudes e tradição na teoria de Alasdair MacIntyre, cf.: Gonçalves, 2012; 2013; Carvalho, 2013; Cardoso, 2011.
} 
as objeções anti-realistas, a saber: determinabilidade racional, estranheza ontológica e internalismo.

Entretanto, os últimos trabalhos de Maclntyre têm apontado para um realismo mais "forte". Um realismo do tipo teísta. Esse tema não foi alvo de análise neste trabalho que tem por escopo apenas evidenciar como a teoria de Maclntyre é capaz de responder às objeções anti-realistas que estão baseadas na distinção entre facto e valor.

\section{Referências}

DAMASCENO, M. M. O Projeto Filosófico Central de Alasdair Maclntyre. Prometeus, filosofia em revista. № 7, janeiro-junho, 2011, p. 95-111.

BRINK, D. O. Realismo Moral. In: SPERBER, M. Dicionário de Ética e Filosofia Moral. Vol 2. São Leopoldo: Editora Unisinos, 2003.

CARDOSO, F. R. O Problema do Relativismo na Teoria Ética de Alasdair Maclntyre. Kínesis, Vol. III, n05, Julho-2011, p. 92-111.

CARVALHO, H. B. A. Ética das Virtudes em Alasdair Maclntyre: Tradição, Racionalidade e Bem Humano. Philosóphos, Goiânia, v.18, № 1, JAN./JUN. 2013, p. 75-101.

GONÇALVES, I. C. R. H. Virtude e Sujeito Moral na Filosofia Moral de Alasdair MacIntyre. Cadernos do PET Filosofia, Vol. 3, n. 5, Jan-Dez, 2012, p. 82-90.

Animalidade, Vulnerabilidade, Dependência e Florescimento Humano no Pensamento de Alasdair Maclntyre. Cadernos do PET Filosofia, Vol. 4, n.8, Jul-Dez, 2013, p. 13-20.

HUME, D. Tratado da natureza humana. Tradução D. Danowski. São Paulo: Editora Unesp/Imprensa Oficial, 2000.

MACINTYRE, A. After Virtue: a study in moral theory. $3^{\text {rd }}$ ed. Notre Dame Press - Notre Dame, Indiana, 2007.

. Whose Justice? Which Rationality? Notre Dame Press - Notre Dame, Indiana, $2008 b$.

Dependent Rational Animals: Why Human Beings Need the Virtues. $6^{\mathrm{a}}$ ed. Open Court Publishing Company; Peru, Illinois, 2008b.

The Tasks of Philosophy: Selected Essays, v.1. Cambridge University Press, New York, 2006. 
PUTNAM, H. Realism with a Human Face. Ed. James Conant. Harvard University Press, 1992.

RAILTON, P. Realismo Moral. In: DARWALL, S.; GIBBARD, A.; RAILTON, P. Metaética: algumas tendências. Organização Darlei Dall'agnol; trad. Janyne Sattler. Florianopolis: Editora UFSC, 2013.

Facts and Values. Philosophycal Topics. Volume XIV, no 2, Fall, 1986.

Doutorando em Filosofia pela Universidade Federal de Santa Maria Mestre em Filosofia/UFPI Professor de Filosofia da UFMA, Campus Bacabal E-mail: joao.caetano@ufma.br 